\title{
Spectroscopic Determination of Charge Formation Efficiency of Organic Photovoltaic Cells
}

\author{
YUTAKA MORITOMO ${ }^{1 *}$, KOUHEI YONEZAWA ${ }^{1}$, AND TAKESHI YASUDA ${ }^{2}$ \\ ${ }^{1}$ Graduate School of Pure \& Applied Physics, University of Tsukuba, Tsukuba 305- \\ 8571, Japan, \\ ${ }^{2}$ Photovoltaic Materials Unit, National Institute for Material Science (NIMS), Tsukuba \\ 305-0047, Japan
}

Corresponding author:

Yutaka Moritomo, e-mail:moritomo.yutaka.gf@u.tsukuba.ac.jp

\begin{abstract}
The internal quantum efficiency $\left(\Phi_{\mathrm{IQ}}\right)$ of an organic photovoltaic (OPV) cell is governed by plural processes, i.e., the carrier formation process at the D/A interface and the carrier transfer process toward the collector electrode. Then, $\Phi_{\mathrm{IQ}}$ can be decomposed into the carrier formation $\left(\Phi_{\mathrm{CF}}\right)$ and carrier transfer efficiencies $\left(\Phi_{\mathrm{CT}}\right)$. By combination of femtosecond time-resolved and electrochemical spectroscopies, we determined absolute values of $\Phi_{\mathrm{CF}}$ of F8T2/PC 71 BM, P3HT/PCBM, and PTB7/PC 71 BM solar cells. We found that $\Phi_{\mathrm{CF}}$ at $400 \mathrm{~nm}$ of the F8T2/PC ${ }_{71} \mathrm{BM}$ cell is higher than those of the $\mathrm{P} 3 \mathrm{HT} / \mathrm{PCBM}$, and $\mathrm{PTB} 7 / \mathrm{PC}_{71} \mathrm{BM}$ cells, although $\Phi_{\mathrm{IQ}}$ at $400 \mathrm{~nm}$ is the lowest.
\end{abstract}

Keyword: Organic photovoltaic cell, carrier formation efficiency, ultrafast spectroscopy, electrochemical spectroscopy.

\section{Introduction}

OPV cells with a bulk heterojunction (BHJ)[1,2] are promising energy conversion devices, because they are flexible, environmental-friendly, and low-cost. The BHJ active layer is a nano-level mixture of a donor (D) polymer and acceptor (A) fullerenes. Extensive time-resolved spectroscopy studies have been carried out to reveal the carrier formation dynamics in a poly(3-hexylthiophene) (P3HT)/[6,6]-phenyl $\mathrm{C}_{61}$-butyric acid methyl ester (PCBM) [3-7] and poly-[4,8-bis[(2-ethylhexyl) oxy]benzo[1,2-b:4,5-b0] dithiophene-2,6-diyl][3-fluoro- 2-[(2 ethylhexyl)carbonyl]thieno[3,4-b] thiophenediyl] (PTB7)/ [6,6]-phenyl $\mathrm{C}_{71}$-butyric acid methyl ester (PC $71 \mathrm{BM)} \mathrm{[8-13]} \mathrm{blend} \mathrm{films.}$ 
Careful analyses of time-dependence of photoinduced absorption (PIA) reveals relative numbers of excitons and carriers against the time $(t)$. Thus, one can determine the lifetime of exciton and/or formation time of carrier, which clarifies the conversion process from exciton to carrier. For example, the exciton-carrier conversion process in PTB7/PC 71 BM blend film takes place within $~ 0.3$ ps.[11] However, interrelation between the carrier formation time/exciton decay time and the photovoltaic properties, e.g., power conversion efficiency (PCE), is unclear.
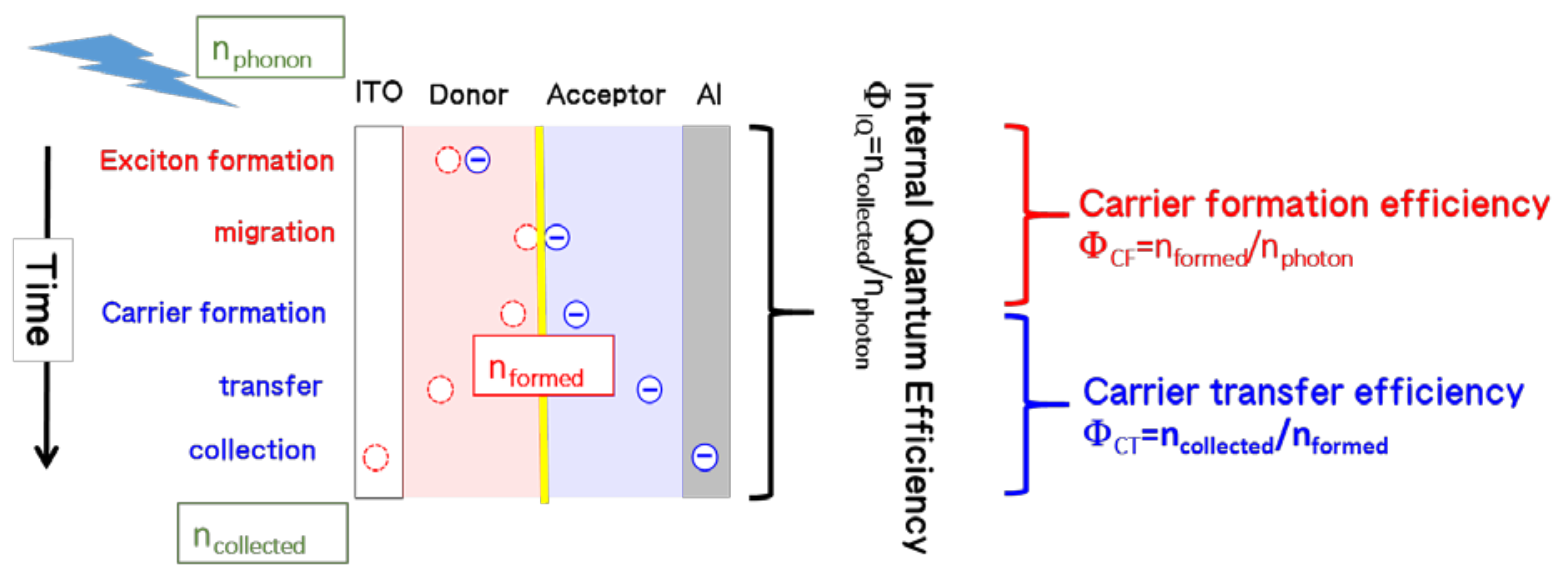

Fig.1: Schematic illustration of photovoltaic process in organic solar cell.

The energy conversion of an OPV cell is governed by plural processes (see Fig.1). In the former process, carriers are formed by the photo-irradiation: the photo irradiation creates a donor exciton $\left(D^{*}\right)$ in the donor region, and $D^{*}$ migrates to the $\mathrm{D} / \mathrm{A}$ interface, and finally, $\mathrm{D}^{*}$ separates into acceptor electron $\left(\mathrm{A}^{-}\right)$and donor hole $\left(\mathrm{D}^{+}\right)$at the interface. In the latter process, the carriers transfer to the collector electrode, and then, collected as photocurrent. This process is in sharp contrast with that of an inorganic photovoltaic (IPV) cell, which consists of only the latter process. The internal quantum efficiency $\left(\Phi_{\mathrm{IQ}}\right)$ is defined by $n_{\text {collected }} / n_{\text {photon}}$, where $n_{\text {collected }}$ is the number of the carriers collected as current and $n_{\text {photon }}$ is the number of the photon absorbed by the device. If we can determine the number of carriers formed at the D/A interface ( $n_{\text {formed }}$ ), we can calculate carrier formation efficiency $\left(\Phi_{\mathrm{CF}}=n_{\text {formed }} / n_{\text {photon }}\right)$ and carrier transfer efficiency $\left(\Phi_{\mathrm{CT}}=\right.$ $\left.n_{\text {collected }} / n_{\text {formed}}\right)$. These efficiencies are important quantities to comprehend the device process, because $\Phi_{\mathrm{IQ}}$ is expressed as $\Phi_{\mathrm{CF}} \times \Phi_{\mathrm{CT}}$. Significantly, the carrier formation process completes within several ps in prototypical OPV cells.[11] Then, the timeresolved spectroscopy can separate the process from the subsequent slow carrier transfer process. 
In this paper, we proposed a spectroscopic method to determine $\Phi_{\mathrm{CF}}$ and applied the method to poly-(9,9'-dioctylfluorene-co-bithiophene) (F8T2)/ PC ${ }_{71} B M$, P3HT/PCBM, and PTB7/PC 71 BM solar cells. We found that $\Phi_{\mathrm{CF}}$ at $400 \mathrm{~nm}$ of the F8T2/PC ${ }_{71} \mathrm{BM}$ cell is higher than those of the P3HT/PCBM, and PTB7/PC ${ }_{71} \mathrm{BM}$ cells, although $\Phi_{\mathrm{IQ}}$ at 400 $\mathrm{nm}$ is the lowest.

\section{Determination of Carrier Formation Efficiency}

The magnitude of $\Phi_{\mathrm{CF}}$ was determined by combination of the femtosecond timeresolved and electrochemical spectroscopies. The former spectroscopy tells us the coefficient ( $\alpha_{\text {photon }}$ ) between the PIA ( $\Delta$ OD) due to carrier and $n_{\text {photon, while the latter }}$ spectroscopy tells us the coefficient ( $\alpha_{\text {carrier }}$ ) between $\Delta \mathrm{OD}$ and $n_{\text {formed. }}$ Then, $\Phi_{\mathrm{CF}}$ is calculated by $\alpha_{\text {photon }} / \alpha_{\text {carrier }}$ In TABLE I, we listed the magnitude of $\alpha_{\text {photon, which are }}$ cited from literatures.[12,14,15] We choose the data at $400 \mathrm{~nm}$ because we can gather reliable $\alpha_{\text {photon }}$ values including the temperature dependence. The $400 \mathrm{~nm}$ photon, however, excites both the donor and acceptor excitons. Then, $\mathrm{D}^{+}$is produced by two process, i. e., $\mathrm{D}^{*} \rightarrow \mathrm{D}^{+}+\mathrm{A}^{-}$and $\mathrm{A}^{*} \rightarrow \mathrm{D}^{+}$and $\mathrm{A}^{-}$. Then, $\Phi_{\mathrm{CF}}$ and $\Phi_{\mathrm{IQ}}$ are the sum of the efficiencies for the two processes. We used the PIA signal due to $\mathrm{D}^{+}$to evaluate $\Phi_{\mathrm{CF}}$, because the $\mathrm{D}^{+}$signal is much stronger than the $\mathrm{A}^{-}$signal.

\begin{tabular}{|r|r|r|r|r|r|}
\hline OPV & $T(\mathrm{~K})$ & $\alpha_{\text {photon }}\left(\mathrm{nm}^{2}\right)$ & $I\left(\mu \mathrm{J} / \mathrm{cm}^{2}\right)$ & $\alpha_{\text {carrier }}\left(\mathrm{nm}^{2}\right)$ & $\Phi_{\text {CF }}$ 400nm \\
\hline F8T2/PC 71 BM & 300 & $0.0027[15]$ & 27 & 0.0041 & 0.66 \\
\hline P3HT/PCBM & 300 & $0.0047[12]$ & 27 & 0.0086 & 0.55 \\
\hline P3HT/PCBM & 80 & $0.0047[12]$ & 27 & 0.0086 & 0.55 \\
\hline PTB7/PC 71 BM & 300 & $0.0076[14]$ & 27 & 0.0130 & 0.58 \\
\hline PTB7/PC 71 BM & 80 & $0.0072[14]$ & 27 & 0.0130 & 0.55 \\
\hline
\end{tabular}

TABLE I. $\alpha_{\text {photon}}, \alpha_{\text {carrier, }}$ and $\Phi_{\text {CF }}$ at $400 \mathrm{~nm}$ for several OPV cells. $\alpha_{\text {photon}}$, and $\alpha_{\text {carrier }}$ were estimated by femtosecond time-resolved and electrochemical spectroscopies, respectively. $I$ is the excitation intensity.

\section{Experimental Procedure}

The electrochemical spectroscopy was performed for the F8T2, P3HT, and PTB7 neat films. The F8T2 neat film was spin-coated on an indium-tin-oxide (ITO) glass substrate from an $o$-dichlorobenzene (o-DCB) solution and annealed for $10 \mathrm{~min}$ at $80{ }^{\circ} \mathrm{C}$ in an inert $\mathrm{N}_{2}$ atmosphere. The P3HT neat film was spin-coated from an $o$-DCB solution and 
annealed for $10 \mathrm{~min}$ at $110^{\circ} \mathrm{C}$ in an inert $\mathrm{N}_{2}$ atmosphere. The PTB7 neat film was spincoated on the substrate from an $o$-DCB solution and was dried in an inert $\mathrm{N}_{2}$ atmosphere. The thicknesses of the F8T2, P3HT, and PTB7 films were 67, 86, and 96 $\mathrm{nm}$, respectively. The electrochemical hole-doping was performed against $\mathrm{Li}$ in propylene carbonate (PC) solution containing $1 \mathrm{~mol} / \mathrm{l} \mathrm{LiClO}_{4}$ in an optical cell with a pair of quartz windows. [16,17] The active area of the film was $\sim 2 \mathrm{~cm}^{2}$, and the current was $100 \mathrm{nA}$. The voltages in the hole-doping process were 3.8, 3.4, and 3.7 $\mathrm{V}$ against $\mathrm{Li}$ for the F8T2, P3HT, and PTB7 films, respectively. The electrochemical differential absorption $\left(\Delta \mathrm{OD} \mathrm{DCC}_{\mathrm{EC}}\right)$ spectrum is expressed as -log $\left(I_{\mathrm{doped}} / I_{\mathrm{non}}\right)$, where $I_{\text {doped }}$ and $I_{\text {non }}$ are the transmission spectra of the hole-doped and non-doped films, respectively.

We fabricated an BHJ solar cells with the structure of ITO / PEDOT:PSS ( 40 $\mathrm{nm}) /$ active layer/LiF $(\sim 1 \mathrm{~nm}) / \mathrm{Al}(\sim 80 \mathrm{~nm})$. Details of fabrication processes are described in the literature. $[6,17]$ In TABLE II, we listed the photovoltaic performances under AM 1.5 solar-simulated light irradiation of $100 \mathrm{~mW} / \mathrm{cm}^{2}$.

\begin{tabular}{|c|c|c|c|c|c|c|}
\hline OPV & $J_{\mathrm{SC}}\left(\mathrm{mA} / \mathrm{cm}^{2}\right)$ & $V_{\mathrm{OC}}(\mathrm{V})$ & FF & PCE (\%) & ФIQ@400nm & $\Phi_{\mathrm{CF}} @ 400 \mathrm{~nm}$ \\
\hline $\mathrm{F} 8 \mathrm{~T} 2 / \mathrm{PC}_{71} \mathrm{BM}$ & 4.28 & 1.00 & 0.43 & 2.28 & 0.35 & 0.66 \\
\hline РЗНТ/РCВМ & 9.9 & 0.60 & 0.64 & 3.80 & 0.60 & 0.55 \\
\hline PTB7/PC ${ }_{71} \mathrm{BM}$ & 14.21 & 0.72 & 0.61 & 6.24 & 0.61 & 0.58 \\
\hline
\end{tabular}

TABLE II. Short-circuit current density $\left(J_{S C}\right)$, open-circuit voltage $\left(V_{\mathrm{OC}}\right)$, fill factor (FF), PCE, $\Phi_{\mathrm{IQ}}$, and $\Phi_{\mathrm{CF}}$ of BHJ solar cells.

\section{Results}
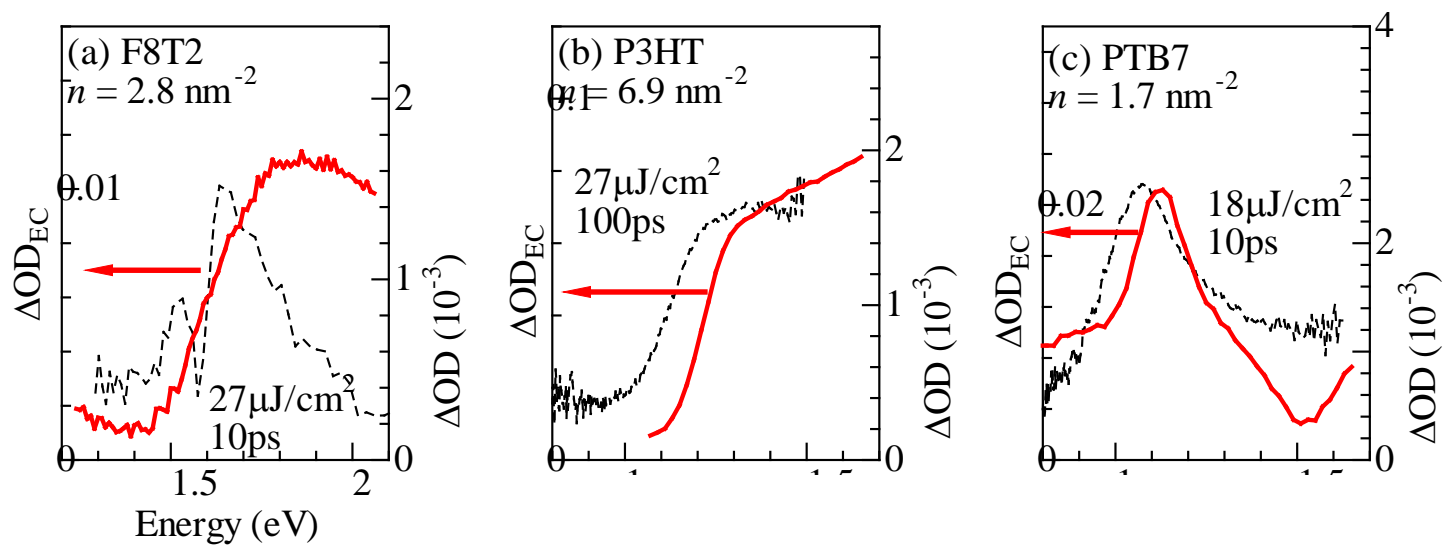

Fig.2: $\triangle \mathrm{OD}_{\mathrm{EC}}$ spectrum of (a) F8T2, (b) P3HT, and PTB7 neat films. $n$ is the density of 
the electrochemically-doped holes. Broken curves are $\triangle \mathrm{OD}$ spectra cited from literatures: (a) F8T2/PC 71 BM[15], (b) P3HT/PCBM,[12] and (c) PTB7/PC 71 BM.[14]
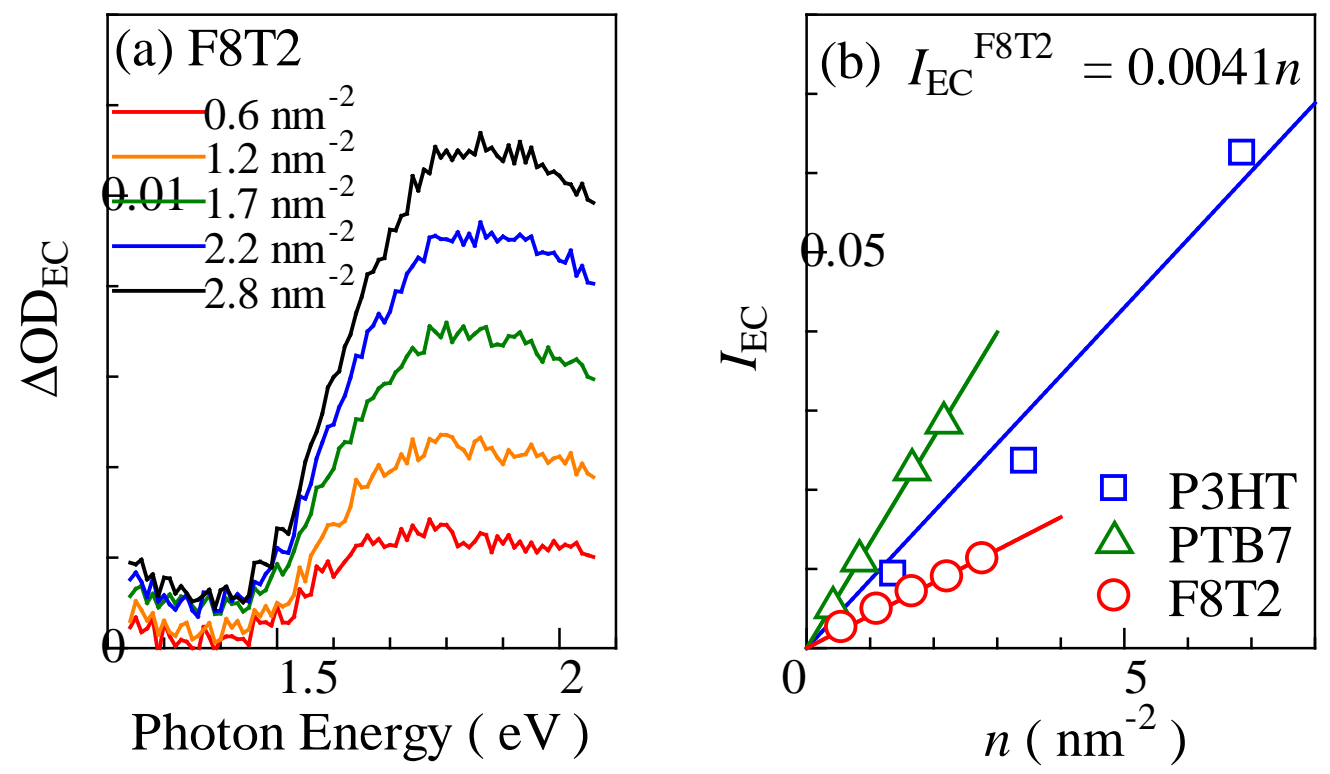

Fig.3: (a) $\triangle \mathrm{OD}_{\mathrm{EC}}$ spectrum of neat F8T2 film against carrier density (n). (b) Intensity ( $\left.I_{\mathrm{EC}}\right)$ of the $\Delta \mathrm{OD}_{\mathrm{EC}}$ spectra against $n$ in the F8T2, P3HT, and PTB7 neat films. The straight lines are the results of least-squares fittings.

Figure 2 shows the $\triangle \mathrm{OD}_{\mathrm{EC}}$ spectra of (a) F8T2, (b) P3HT, and PTB7 neat films. In all the polymers, the profiles of the $\Delta \mathrm{OD}_{\mathrm{EC}}$ spectra are similar to those of the $\Delta \mathrm{OD}$ spectra. This indicates that the absorption should be ascribed to $\mathrm{D}^{+}$. Figure 3 (a) shows the $\Delta \mathrm{OD}_{\mathrm{EC}}$ spectra of the neat F8T2 film against carrier density $(n)$. Figure 3 (b) shows intensity ( $I_{\mathrm{EC}}$ at $1.8 \mathrm{eV}$ ) of the $\Delta \mathrm{OD}_{\mathrm{EC}}$ spectra of F8T2 neat film against $n$. The magnitude of $I_{\mathrm{EC}}$ increases in proportional to $n$. $\alpha_{\text {carrier }}$ was determined by least-squares fitting, as indicated by straight line. With use of $\alpha_{\text {carrier }}$ and $\alpha_{\text {photon}}$, we calculated $\Phi_{\mathrm{CF}}$ and listed in TABLE I and TABLE II.

\section{Discussion}




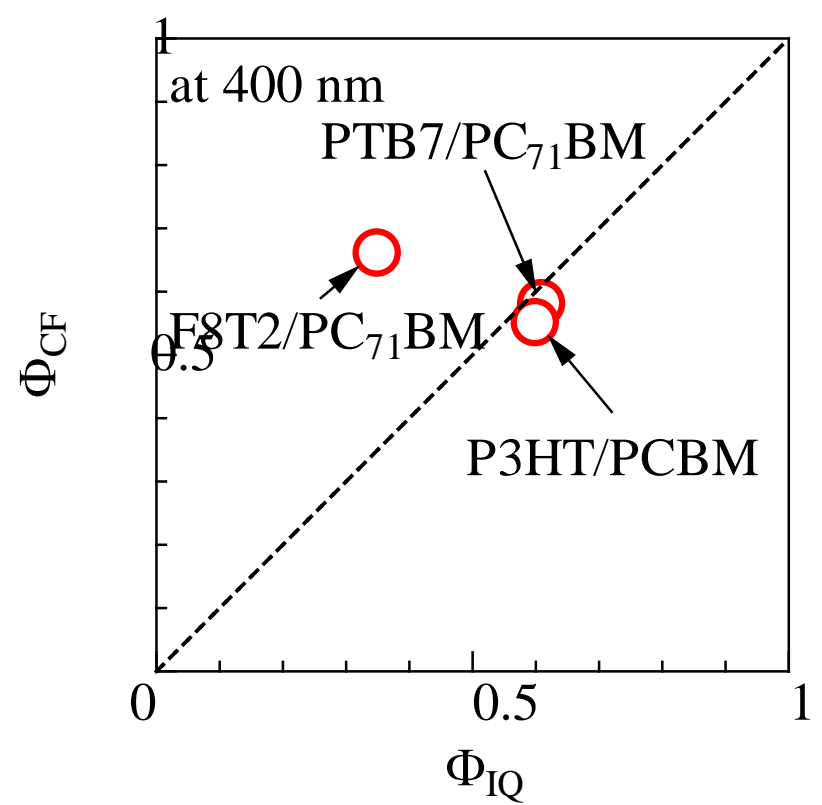

Fig.4: Interrelation between $\Phi_{\mathrm{CF}}$ and $\Phi_{\mathrm{IQ}}$ for F8T2/PC ${ }_{71} B M$, P3HT/PCBM, and PTB7/PC 71 BM solar cells.

We plotted in Fig.4 interrelation between $\Phi_{\mathrm{CF}}$ and $\Phi_{\mathrm{IQ}}$ for F8T2/PC ${ }_{71} \mathrm{BM}$, P3HT/PCBM, and PTB7/PC ${ }_{71} \mathrm{BM}$ solar cells. As seen in TABLE II, PCE of the PTB7/PC ${ }_{71} \mathrm{BM}$ cell is larger than that of the P3HT/PCBM cell. However, the $\Phi_{\mathrm{IQ}}$ values at $400 \mathrm{~nm}$ are nearly the same between the two solar cells. Our spectral analysis revealed that the $\Phi_{\mathrm{CF}}$ values at $400 \mathrm{~nm}$ are approximately the same between the two solar cells. Then, the larger PCE in the PTB7/PC 71 BM cell should be ascribed to the low band-gap nature of the PTB7. Looking at Fig. 4, we found that $\Phi_{\mathrm{CF}}$ of the F8T2/PC ${ }_{71} \mathrm{BM}$ cell is higher than those of the P3HT/PCBM and PTB7/PC ${ }_{71} B M$ cells, although $\Phi_{I Q}$ at $400 \mathrm{~nm}$ is the lowest. We suspect that the high- $\Phi_{\mathrm{CF}}$ is ascribed to the nano-level mixing of F8T2 and $\mathrm{PC}_{71} \mathrm{BM}$. Our spectral analysis revealed that the low- $\Phi_{\mathrm{IQ}}$ of the F8T2/PC ${ }_{71} \mathrm{BM}$ cell should be ascribed to the worse carrier transfer efficiency $\left(\Phi_{\mathrm{CF}}\right)$.

\section{Conclusion}

We proposed a spectroscopic method to determine $\Phi_{\mathrm{CF}}$ and applied the method to the F8T2/PC 71 BM, P3HT/PCBM, and PTB7/PC 71 BM solar cells. Our method is applicable to the fast screening of the photovoltaic materials, because the high- $\Phi_{\mathrm{CF}}$ should be one necessary condition for a high-PCE solar cell. The spectroscopic determination of $\Phi_{\mathrm{CF}}$ is a powerful tool to comprehend the complicated process of organic solar cells.

\section{References}


1. Hiramoto, M., Fujiwara, H., and Yokoyama, M. (1991). Appl. Phys. Lett., 58, 1062 .

2. Sariciftci, N. S., Smilowitz, L., Heeger, A. J., and Wudl, F. (1992). Science, 285, 1474.

3. Hwang, I.-W., Moses, D., and Heeger, A. J. (2008). J. Phys. Chem., C 112, 4350.

4. Guo, J., Ohkita, H., Benten, H., and Ito, S. (2009). J. Am. Chem. Soc., 131, 16869.

5. Guo, J., Ohkita, H., Benten, H., and Ito, S. (2010). J. Am. Chem. Soc., 132, 6154.

6. Yonezawa, K., Ito, M., Kamioka, H., Yasuda, T., Han, L., and Moritomo, Y. (2012). Adv. Opt. Technol., 2012, 316045.

7. Marsh, R. A., Hodgkiss, J. M., Albert-Seifried, S., and Friend, R. H. (2010). Nano Lett., 10, 923.

8. Guo, J., Liang, Y., Szarko, J., Lee, B., Son, H.-J., Rolczynski, B. S., Yu, L., and Chen, L. X. (2010). J. Phys. Chem., B 114, 742.

9. Szarko, J. M., Guo, J.-C., Rolczynski, B. S., and Chen, L. X. (2011). J. Mater. Chem., 21, 7849.

10. Rolczynski, B. S., Szarko, J. M., Son, H. J., Liang, Y., Yu, L., and Chen, L. X. (2012). J. Am. Chem. Soc., 134, 4142.

11. Yonezawa, K., Kamioka, H., Yasuda, T., Han, L., and Moritomo, Y. (2013). Jpn. J. Appl. Phys., (2013) 52, 062405.

12. Yonezawa, K., Kamioka, H., Yasuda, T., Han, L., and Moritomo, Y. (2013). Appl. Phys. Lett., 103, 173901.

13. Akaba, T., Yonezawa, K., Kamioka, H., Yasuda, T., Han, L., and Moritomo, Y. (2013). Appl. Phys. Lett., 102, 133901.

14. Moritomo, Y., Yonezawa, K., and Yasuda, T. (2014). Appl. Phys. Lett., 105, 073902.

15. Yonezawa, K., Ito, M., Kamioka, H., Yasuda, T., Han, L., and Moritomo, Y. (2011). Appl. Phys. Express, 4122601.

16. Harbeke, G., Baeriswyl, D., Kiess, H., and Kobel, W. (1986). Phys. Scr., T13, 302.

17. Yasuda, T., Yonezawa, K., Ito, M., Kamioka, H., Han, L., and Moritomo, Y. (2012). J. Photopolym. Sci. Technol., 25, 271. 